Светлана Творогова

\title{
ЛЮДИ. ЗАБОТА. ЦЕРКОВЬ. КТО КОМУ ПОМОГАЕТ И ЧТО ИЗ ЭТОГО ПОЛУЧАЕТСЯ: СОЦИАЛЬНАЯ РАБОТА В ПРАВОСЛАВНЫХ ПРИХОДАХ РОССИИ
}

\begin{abstract}
Орешина Д.А., Батанова П.В., Забаев И.В., Павлюткина Е.Л. (2018) «Партнерский приход»: Сотрудничество священников и мирян в развитии социальной деятельности в приходах РПЦ в начале XXI века. Москва: Издательство ПСтГУ. 320 с. ISBN: 978-5-7429-1146-3
\end{abstract}

DOI: $10.17323 / 727-0634-2019-17-3-473-477$

Что происходит в обществе, когда меняется привычный порядок? Социальные процессы в России дают богатую пищу для наблюдений, анализа и размышлений. Корректно сформулированный исследовательский вопрос и правильно собранные данные позволяют разобраться в деталях едва уловимого процесса становления новых институтов: можно увидеть, как возникают новые формы работы; появляются новые акторы, а их приход перекраивает сложившийся порядок; как небольшие изменения оказываются способными вызвать серьезные социальные трансформации. Внимание к деталям в подобных исследованиях необходимы, чтобы внутренние ограничения исследователей не помешали увидеть то новое, что приходит на смену привычному. Иными словами, хорошее исследование дает редкую возможность заглянуть в будущее.

Одной из сфер общественной жизни, где изменения правил игры особенно заметно, является социальная политика. Переход к рыночной экономике привел к значительному сокращению социальных обязательств государства и государственных предприятий-граждане были вынуждены искать альтернативные способы решения своих проблем. В некоторых случаях индивидуальные усилия способны привести к успеху, но часто люди объединяются вокруг существующих социальных институтов, чтобы обрести поддержку и контакты. О том, как именно это происходит, как индивидуальные усилия нуждающихся в помощи управляются существующим институтом, как спонтанно возникающие социальные практики обретают границы, можно судить по книге «"Партнерский приход": Сотрудничество священников и мирян в развитии социальной деятельности в приходах РПЦ в начале XXI века».

Книга построена на данных четырех исследований, три из которых общероссийские. Данные двух проектов можно назвать количественными,

Светлана Викторовна Творогова-к.с.н., независимый исследователь, Брюссель, Бельгия. Электронная почта: svetlana.tvorogova@gmail.com 
два других сочетали в себе количественную методологию с неформализованными, полуформализованными и глубинными интервью. Разнообразие каналов и способов сбора данных позволило авторам комплексно рассмотреть становление новых форм работы церкви как института, а охват территории всей страны- подробно остановиться на региональных и локальных различиях между формами и масштабами проводимой разными приходами социальной работы.

С уходом государства из многих сфер социальной помощи в начале 1990-х гг. в российском обществе образовалось свободное пространство для благотворительной деятельности. Экономические сложности переходного периода и новизна экономического положения для россиян, у которых отсутствовал опыт жизни в условиях рыночной экономики, сделали это поле деятельности востребованным. РПЦ наряду с другими, активно включилась в благотворительную работу, став площадкой для совместной активности тех, кто готов помочь, и тех, кому нужна помощь или поддержка. Усиление социального неравенства- незнакомое для российского общества- поставило вопросы о том, каким образом организовывать свою жизнь в связи с новым уровнем доходов, и тут готовность церкви стать местом для взаимодействия оказалась как нельзя кстати.

Д.А. Орешина с соавторами решили не ограничиваться определением социальной работы как помощи нуждающимся, но предложили свое понимание той роли, которую современный церковный приход способен играть в жизни так или иначе связанных с ним людей. Эта модель (на с. 21 монографии она представлена в графическом виде) показывает работу прихода как систему взаимосвязанных действий, результат общего взаимодействия всех тех, кто реализует самые разные формы поддержки нуждающихся через церковь. Для авторов церковный приход является местом, где осмысляется, актуализируется и приумножается социальный капитал, он (церковный приход) также служит каналом доступа к социальному капиталу объединенных церковью людей. Именно это помогает церкви быть источником социальной поддержки в самом широком смысле.

Социальный капитал как форма влияния сообществ на социальные макропроцессы начал активно исследоваться в последние десятилетия. Работы Роберта Патнама (Putnam 1993; 1995) показали, каким образом повседневное взаимодействие людей в рамках формальных и неформальных ассоциаций влияет на способность общества быть восприимчивым к демократическим институтам. Привычка поддерживать отношения с большим числом разных, не всегда близких людей учит достижению договоренностей, которые, в свою очередь, важны для эффективной работы выборных структур. У людей появляется готовность считаться с иными мнениями, восприимчивость к диалогу и совместной работе вопреки разногласиям, способность воспринимать другие точки зрения не как что-то личное, но как поле для достижения компромиссов, благодаря 
которым разные люди вместе движутся вперед. Именно подобный аспект социального капитала - совместная работа в приходском сообществе, подспудно подводящая к освоению ценностей гражданского общества,рассматривается авторами.

В книге предлагается типология форм социальной работы приходов, подробно разбирается, что стоит за указанными различиями, и почему они важны. Основной вопрос, который ставят перед собой авторы, можно сформулировать так: почему приходы столь сильно различаются по проводимой в них социальной работе? Рассматривая стандартные предположения о важности ресурсов разного типа, авторы замечают, что их наличие не всегда приводит к формированию деятельного прихода, внутри которого социальная работа становится самоорганизованной и расширяющейся деятельностью. Они показывают, как большие приходы в крупных населенных пунктах с гетерогенным населением способны предлагать широкий спектр форм поддержки, но при этом и в небольшом населенном пункте активный и целеустремленный настоятель способен преобразить разобщенное общество вокруг себя, развернув работу без наличия тех же ресурсов. Это говорит о генерировании социального капитала настоятелем: усиление взаимодействия внутри разобщенного сообщества позволяет решать широкий круг задач.

Подобные выводы соотносятся с идеями о роли энтузиастов в развитии церковных сообществ: например, исследователи (Stark, Bainbridge 1985; Kelley 1986) показывают, как важны личные контакты между прихожанами для роста и развития прихода, разрабатывают идею об энтузиастах или активистах прихода, благодаря которым он обретает способность сплачивать людей вокруг себя (см. также Iannaccone 1994; Iannaccone et al. 1995; Medcalfe, Sharp 2012). Сравнение этих работ с книгой Орешиной и коллег показывает, что в российских условиях важны не только активные прихожане, но и создающий условия для их активной деятельности настоятель. Вероятно, дефицит опыта и практик церковной социальной работы требует целенаправленной деятельности по их созданию и распространению, и тут важна роль настоятеля как лидера и первопроходца. Иными словами, настоятель как лидер и организатор способен компенсировать дефицит ресурсов в приходе, может организовать работу других и оказаться «генератором» социального капитала-именно он дает импульс изменениям и поддерживает их в дальнейшем.

В двух частях книги подробно рассмотрено, как по-разному настоятели интерпретируют свои задачи и к чему это приводит; представлены и подробно проанализированы социальные сети приходов или настоятелей. Наряду с ролью настоятеля (Часть 1) в книге подробно рассматриваются и роли его помощников (Часть 2), проводящих социальную работу. Количественный характер используемых во второй части данных позволяет получить подробное представление о масштабах явления и возможных 
тенденциях его развития, тогда как данные интервью из первой части позволяют лучше понять как поставленные проблемы, так и ход рассуждений и анализа.

Авторы активно разрабатывают понятийный аппарат изучаемой темы, в частности, подробно рассматривают, как интерпретировать понятие прихода, приходской работы и занятых ею прихожан. Такая проработка терминов представляется крайне важной в виду дефицита традиции российских исследований в данной области. Очевидно, что понятия, сформированные в других школах (авторы активно цитируют американскую и европейские школы изучения приходской жизни), должны быть адаптированы к российским реалиям, в каких-то случаях требуется уточнение и, возможно, альтернативные формулировки или новые понятия. В этом отношении Орешина с коллегами делают очень полезный экскурс в практику работы РПЦ, описывая организационные схемы, регулирующие социальную работу церкви. Таким образом показываются институциальные рамки, которые конкретные люди в конкретных приходах наполняют смыслом, адаптируя их под свои задачи и возможности.

Особенно значительными в этой связи представляются следующие теоретические новации. Так, в первой главе показано, как богатство текущих практик оказывается сложно вместить в существующие аналитические рамки, и насколько целесообразнее рассматривать их развитие в контексте социальной политики и трансформации социальных институтов. Такая постановка вопроса открывает большие возможности для междисциплинарных исследований. В пятой главе ярко и образно показаны возможности воздействия между церковным приходом и местным сообществом. Эмпирический материал очень богат и полезен не только для тех, кто интересуется социальной работой или работой религиозных учреждений, но и для тех, кто изучает управление или социальное воздействие организаций.

Для многих российских исследователей поднятая тема остается довольно далекой, если не сказать экзотичной, но возможность в ней разобраться важна для понимания существенных аспектов жизни современного российского общества- например, для понимания многообразия способов реализации социально значимых проектов. В то же время, можно сделать разные предложения по тому, как книгу можно было бы улучшить: например, в текущей версии есть некоторая разбалансированность двух ее частей, связь между которыми остается слабо прописанной, анализ некоторых затронутых авторами вопросов следовало бы усилить или расширить. Однако поднятая тема озвучена едва ли не впервые, не изучалась на столь подробной эмпирической базе, поэтому является приглашением к дальнейшей дискуссии. 
Svetlana Tvorogova

PeOple. Care. ChuRch.

WHO HELPS WHOM AND WHAT DOES IT LEAD TO? SOCIAL WORK IN RUSSIAN ORTHODOX CONGREGATIONS

D. A. Oreshina, P. V. Batanova, I.V. Zabaev, E. L. Pavlyutkina (2018) 'Partnerskiy prikhod': Sotrudnichestvo svyashchennikov i miryan $v$ razvitii sotsial'noy deyatel'nosti $v$ prikhodakh $R P T s$ nachale XXI veka ['Partnership Parish': Interactions between priests and lay people on social care in ROC parishes, beginning of $21^{\text {st }}$ century]. Moscow: PSTGU Press. 320 p. ISBN: 978-5-7429-1146-3

DOI: $10.17323 / 727-0634-2019-17-3-473-477$

\section{References}

Iannaccone L. R. (1994) Why Strict Churches are Strong. American Journal of Sociology, 99 (5): 1180-1211.

Iannaccone L. R., Olson P. and Stark R. (1995) Religious Resources and Church Growth. Social Forces, 74 (2): 705-731.

Kelley D. (1986) Why Conservative Churches are Growing: A Study in the Sociology of Religion. Macon, GA: Mercer University Press.

Medcalfe S., Sharp C. (2012) Enthusiasm and Congregation Growth: Evidence from the United Methodist Church. International Journal of Business and Social Science, 3 (9):30-39.

Putnam R. (1993) Making Democracy Work: Civic Traditions in Modern Italy. Princeton: Princeton University Press.

Putnam R. (1995) Bowling Alone: America's Declining Social Capital. Journal of Democracy, 6 (1): 65-78.

Stark R., Bainbridge W.S. (1985) The Future of Religion. Berkeley: University of California Press.

Svetlana Tvorogova - PhD (Kandidat Nauk) in Sociology, freelance researcher, Brussels, Belgium. Email: svetlana.tvorogova@gmail.com 